\title{
O desafio historiográfico: o estudo da operação historiográfica de Capistrano de Abreu
}

The Historiographical Challenge: the Study of Capistrano de Abreu's Historiographical Operation

OLIVEIRA, Maria da Glória de. Crítica, método e escrita da história em João Capistrano de Abreu. Rio de Janeiro: Editora FGV, 2013. 144 p.

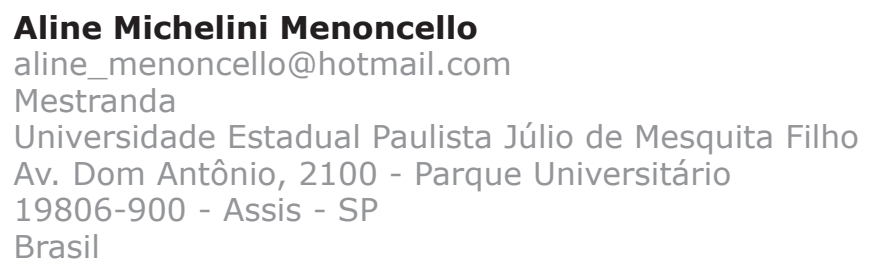

Capistrano de Abreu; Operação historiográfica; História da historiografia.

Keywords

Capistrano de Abreu; Historiographical operation; History of historiography. 
A historiadora Maria da Glória de Oliveira, professora de Teoria da História e História da Historiografia na Universidade Federal Rural do Rio de Janeiro, publicou em 2013 a obra Crítica, método e escrita da história em João Capistrano de Abreu. O livro é fruto de sua dissertação de mestrado, primeiro trabalho de grande fôlego a marcar o momento em que Oliveira enfrentou um grande desafio: analisar a escrita da história de um dos autores mais citados e estudados pela historiografia brasileira, João Capistrano Honório de Abreu (1853-1927).

Capistrano de Abreu, o autor que possibilitou novos rumos para a historiografia brasileira no início do século $X X$, conquistou um lugar de destaque entre os intelectuais brasileiros e foi reconhecido como "mestre" dos estudos históricos, geográficos e etnográficos pela Sociedade Capistrano de Abreu (1927-1969). ${ }^{1}$ José Honório Rodrigues (1913-1987), membro da sociedade e um dos seus maiores estudiosos, foi responsável pela organização da correspondência ativa do "mestre" e, em 1953, ao escrever um artigo para o dossiê da Revista do Instituto Histórico e Geográfico Brasileiro (IHGB)² em homenagem ao historiador cearense, destacou a importância de Capistrano para a historiografia brasileira. Outro estudo recente e muito importante é o da historiadora Rebeca Gontijo (2013), ${ }^{3}$ que investiga os problemas relativos à identidade do historiador em dois sentidos: como uma construção coletiva que destaca um indivíduo e sua produção em uma dada tradição intelectual e como a soma dos investimentos feitos pelo próprio historiador em seu trabalho historiográfico. E foi por meio da memória, da historiografia e da escrita de si

276 (de Capistrano de Abreu) que Gontijo investigou a construção da identidade de Capistrano de Abreu como historiador.

Estudos como os destacados acima são caros ao campo de investigação da história da historiografia, que se interroga a respeito de uma dada cultura histórica e da função do historiador em uma determinada sociedade. Em seu estudo e para interrogar o ofício do historiador em Crítica, método e escrita da história em João Capistrano de Abreu (2013), Maria da Glória de Oliveira inspirou-se na noção de operação historiográfica de Michel de Certeau (2010). Esse aporte teórico deu a Oliveira o fundamento para problematizar a obra de Capistrano analisando o /ugar social, as práticas e a escrita. Desse modo, Oliveira organizou a sua narrativa em quatro capítulos. No primeiro, ela descreveu a concepção de história de Capistrano relacionando-a com sua biografia; em seguida, ela identificou o projeto historiográfico do autor ao analisar os artigos que ele escreveu a respeito da produção de Francisco Adolfo de Varnhagen; no terceiro capítulo, a historiadora narrou os procedimentos usados por Capistrano em sua prática como historiador; e finalizou o livro analisando de que maneira o procedimento da crítica documental do autor se articula à sua produção

\footnotetext{
${ }^{1}$ A dissertação de mestrado de Ítala Byanca Morais da Silva (2008) é uma análise da construção da memória de Capistrano realizada pela Sociedade Capistrano de Abreu. Um dos desdobramentos da dissertação é o artigo "Anotar e prefaciar a obra do 'mestre': reflexões de José Honório Rodrigues sobre Capistrano de Abreu"; nele, Silva busca compreender a construção de José Honório Rodrigues sobre Capistrano.

2 É importante destacar que a Revista do IHGB - v. 221 - publicada em 1953 foi uma edição que reuniu artigos em homenagem a Capistrano de Abreu.

${ }^{3} \mathrm{~A}$ obra de Gontijo é fruto da tese de doutorado defendida no mesmo ano da dissertação de mestrado de Oliveira.
} 
historiográfica. A obra também tem um anexo, a cronologia, no qual Oliveira destaca momentos importantes da vida e da obra do historiador cearense.

Maria da Glória de Oliveira apresenta-nos um personagem polêmico no primeiro capítulo, intitulado "Entre o futuro e o passado: o historiador de transição". Capistrano de Abreu nasceu em Maranguape, província do Ceará, no ano de 1853 e mudou-se para a cidade da Corte em 1875. Foi nomeado bibliotecário da Biblioteca Nacional em 1879 e, quatro anos mais tarde, passou no concurso para professor do Colégio Pedro II, onde ministrou aulas de Corografia e História do Brasil. Em 1887 foi admitido como sócio efetivo do Instituto Histórico Geográfico Brasileiro. Ele expressava suas ideias por meio da correspondência trocada com diversos letrados do período e em artigos publicados nos periódicos da época, tais como Gazeta de notícias, Jornal do commercio e O globo. Com ideias divergentes de seus coetâneos, afirmava o papel preponderante dos indígenas para a formação nacional e, ainda, uma certeza quanto a como a história do Brasil deveria ser escrita. Reconhecido pelos seus contemporâneos, Capistrano esboçava "a sua própria concepção de história" (OLIVEIRA 2013, p. 28), concepção essa advinda das leituras de autores estrangeiros, lidos por todos os historiadores da geração de 1870: Henry Thomas Buckle, Herbert Spencer, Hippolyte Taine e outros (ALONSO 2002; OLIVEIRA 2013).

No segundo capítulo, "Como deveria ser escrita a história da nação?", Oliveira, ao analisar dois artigos do polêmico historiador, o "Necrológio de Francisco Adolfo de Varnhagen" (1878) e o ensaio "Sobre o visconde de Porto Seguro" (1882), procurou mostrar de que modo Capistrano quebrou com o "Quadros de Ferro" de Varnhagen. Encontramos neste capítulo um Capistrano mais complexo; ele é mostrado como um crítico que reconhece o trabalho do autor de História geral do Brasil, mas que considerava que "[...] sua obra ainda se mostrava imperfeita e, por isso, demandava um cuidadoso exame crítico" (OLIVEIRA 2013, p. 50). Em seguida, é apresentado como um autor preocupado com o trabalho científico, pois pensava que "[...] sem o auxílio da nova "ciência sociológica", não era possível perceber as relações constitutivas dos diferentes aspectos e fatores de um povo" (OLIVEIRA 2013, p. 53). E, ainda, como um pesquisador que sabia que, para superar Varnhagen, "seriam necessários o adiantamento e a acumulação dos estudos históricos" (OLIVEIRA 2013, p. 63).

Nos dois primeiros capítulos a autora demonstra, de maneira habilidosa, as implicações dos lugares sociais nas escolhas, a atividade historiográfica e as críticas de Capistrano de Abreu, ou seja, ela descreve de que modo a Biblioteca Nacional, o Colégio Pedro II e o IHGB foram importantes para o historiador forjar a sua concepção de história e assim conseguir problematizar e revisar os escritos de Varnhagen. Nos terceiro e quarto capítulos do livro, a historiadora deu sequência à análise certeauniana, empenhando-se em investigar as práticas científicas e a escrita historiográfica de Capistrano.

No terceiro capítulo, "O momento do arquivo", a autora apresenta-nos um Capistrano de Abreu inquieto e incansável. Ele passava horas lendo, reunindo, compilando e interpretando os documentos e fez da Biblioteca Nacional e do acervo do IHGB o seu "laboratório científico". Oliveira narrou 
alguns momentos em que as operações metódicas do historiador foram decisivas para solucionar os problemas históricos causados pela falta de documentos. "Se a história se faz com documentos, a do Brasil dificilmente poderia ser feita sem que se recorresse ao testemunho dos cronistas dos tempos coloniais" (OLIVEIRA 2013, p. 73). Desse modo, Capistrano, ao encontrar a obra História do Brasil (1627), do cronista frei Vicente do Salvador, deu início ao trabalho de revisão para comprovar a fidedignidade da obra. Para identificar a autoria dos textos, Capistrano utilizava a "[...] meticulosa combinação de provas 'extrínsecas' e 'intrínsecas' [...]" (OLIVEIRA 2013, p. 82) e, quando não havia documentos, usava o raciocínio conjectural para verificar a plausibilidade histórica (OLIVEIRA 2013).

Em "A história do Brasil entre a anotação e a escrita", título do quarto capítulo de sua obra, Oliveira descreve a última fase da operação historiográfica de Capistrano, a da escrita; momento dramático para ele, pois "[...] a obrigação de colocar 'o último ponto', longe de provocar a satisfação de tarefa cumprida, aguçava-Ihe a percepção de suas lacunas" (OLIVEIRA 2013, p. 123). Os povos indígenas, objeto recorrente de suas preocupações, foram comtemplados pelo historiador, que buscou compreender sua língua e costumes em Os bacaeris (1895) e Rã-txa hu-ni-ku-i: a língua dos caxinauás do rio Ibuaçu (1914). A historiadora, ao analisar a escrita dessas obras, compreende que "a prática etnográfica de Capistrano apontava, assim, para a necessidade de produzir uma materialidade documental na qual faltavam os vestígios escritos" (OLIVEIRA

278 2013, p. 111). Outro trabalho que tomou muito tempo do historiador foi a revisão da obra de Varnhagen História Geral do Brasil, pois, como observa Oliveira (2013, p. 118): "trata-se, pois, não tanto de contestá-lo, mas de seguir o rastro de suas numerosas fontes, identificar-lhes a procedência, confrontá-las com outros testemunhos, de modo a ratificar, ou seja, tornar mais exata e menos incompleta a sua narrativa". Por fim, Oliveira analisou a escrita da obra Capítulos de história colonial (1907). Capistrano, nessa obra, não usou os recursos de apêndice e nota de rodapé para a apresentação de provas, mas "os Capítulos não deixariam de ser reverenciados por suas características propriamente historiográficas, como texto dotado de coerência própria, perpassado de fatos precisos e marcas de historicidade" (OLIVEIRA 2013, p. 122),

Assim, a obra Crítica, método e escrita da história em João Capistrano de Abreu oferece aos leitores e pesquisadores da área da história da historiografia um toque de proximidade com o historiador cearense a partir dos vários trechos de sua correspondência ativa transcritos por Maria da Glória de Oliveira. É, sobretudo, uma obra que deslinda o universo de um historiador que viveu entre fins do século XIX e começo do século XX, pois Oliveira, ao enfrentar o desafio historiográfico de descrever a operação historiográfica de Capistrano de Abreu, apresenta-nos um pesquisador de carne e osso; em função dos prazos e de sua dificuldade de colocar "o último ponto", suas obras são trabalhos cheios de lacunas e passíveis de revisão, mas também constituem um modelo de escrita da história nacional no início do século XX. 


\section{Referências bibliográficas}

ALONSO, A. Ideias em movimento: a geração 1870 na crise do Brasil-Império.

São Paulo: Paz e Terra, 2002.

CERTEAU, Michel de. A Operação historiográfica. In: A escrita da história. Traduzido por Maria de Lourdes Menezes; revisão técnica de Arno Vogel, $2^{a}$ edição. Rio de Janeiro: Forense Universitária, 2010, p. 65-119.

GONTIJO, Rebeca. O velho vaqueano Capistrano de Abreu (1853-1927): memória, historiografia e escrita de si. Rio de Janeiro: 7 letras, 2013.

OLIVEIRA, Maria da Glória de. Crítica, método e escrita da história em João Capistrano de Abreu (1853 - 1927). 2006. Dissertação (Mestrado em História), Programa de Pós-Graduação em História, Universidade Federal do Rio Grande do Sul, Porto Alegre, 2006.

RODRIGUES, José Honório. Capistrano e a historiografia brasileira. Revista do IHGB, v. 221, p. 120-138, 1953.

SILVA, Ítala Byanca Morais da. Anotar e prefaciar a obra do "mestre": reflexões de José Honório Rodrigues sobre Capistrano de Abreu. História da historiografia, n. 3, p. 83-105, 2009.

Les morts vont vite: a Sociedade de Capistrano de Abreu e a construção da memória de seu patrono na historiografia brasileira (19271969). 2008. Dissertação (Mestrado em História). Programa de PósGraduação em História, Universidade Federal do Rio de Janeiro, 2008. 